\section{Background and Goal}

Despite the advances in pain pathophysiology understanding and its inclusion as a clinical target in health care quality, the incidence of failure in the management of postoperative pain is high, increasing morbidity in surgical patients even in low- complexity procedures. (1) It's estimated that only 1 in 4 patients receive proper pain management in postoperative care. (1) Epidural technique with local anaesthetic prevents the pain pathophysiological responses better than systemic analgesia if the catheter is congruent with the surgical site. (2, 3) Reviewing previous post operative cases at HCPA, poor pain management and incongruent epidural catheters was found. Based on these data, we evaluated the quality of postoperative analgesia through the congruence of the catheters before and after the introduction of a quality improvement plan among anaesthetists at HCPA, a tertiary institution that proceeds about 13,600 surgeries per year.

\section{Material and Methods}

We defined strategies to improve the quality of postoperative epidural analgesia.

Plan: identification of incongruent epidural catheters (42\%) and the goal set to improve the congruence to $90 \%$.

Do: implementation of an improvement plan consisting of weekly cases discussion, registrar tutorials and online tutorials.

Check: electronic post operative care monitoring and identification of catheter congruence.

Act: definition of the new process as local standard.

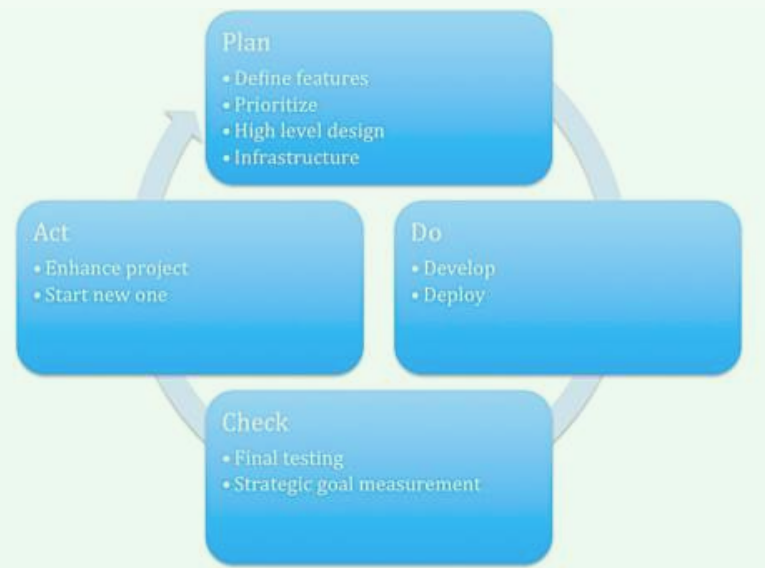

\section{Results}

Based on post-operative follow up data of 592 epidural anaesthesia/analgesia patients, from July 2012 to July 2013, the procedures were divided according to surgical site: thoracic; upper abdominal, middle abdominal, lower abdominal and lower extremity. The insertion level was considered congruent when the epidural catheter was inserted according to the table:

\begin{tabular}{|c|c|c|}
\hline Local of Incision & $\begin{array}{c}\text { Examples of Surgical } \\
\text { Procedures }\end{array}$ & $\begin{array}{c}\text { Congruent Epidural } \\
\text { Catheter Placement }\end{array}$ \\
\hline Thoracic & $\begin{array}{c}\text { Lung reduction, } \\
\text { radical mastectomy, } \\
\text { thoracotomy, } \\
\text { thymetomy }\end{array}$ & T4-8 \\
\hline Upper abdominal & $\begin{array}{c}\text { Cholecystectomy, } \\
\text { esophagectomy, } \\
\text { gastrectomy, } \\
\text { hepatic resection, } \\
\text { whipple procedure }\end{array}$ & $\mathrm{T} 6-8$ \\
\hline Middle abdominal & $\begin{array}{c}\text { Cystoprostatectomy, } \\
\text { nephrectomy }\end{array}$ & $\mathrm{T} 7-10$ \\
\hline Lower abdominal & $\begin{array}{c}\text { Abdominal aortic, } \\
\text { aneurysm repair, } \\
\text { colectomy } \\
\text { radical prostatectomy, } \\
\text { total abdominal } \\
\text { hysterectomy }\end{array}$ & $\mathrm{T} 8-11$ \\
\hline Lower extremity & $\begin{array}{c}\text { Femoral-popliteal bypass, } \\
\text { totat hip or total knee } \\
\text { replacement }\end{array}$ \\
\hline
\end{tabular}

While 58\% (170) patients were classified as incongruent, only $42 \%$ were congruent (124).

With the PDCA intervention, educational strategies to consultant anaesthetists and anaesthetic trainees were implemented.

A new analyses of 241 patients followed by the Acute Pain Service from July 2015 to February 2016 found only 16,7\% (41) of the catheters incongruent with surgical site and 83,3\% (200) of congruence. These numbers represent an outcome improvement of $98,3 \%$, overcoming the initial goal, likely to be result of the improvement strategies.

Analysing by surgical site, the statistical significant results $(\mathrm{P}<0,05)$ appeared at thoracic, upper, middle and inferior abdominal sites, improving $28,1 \% ; 64,6 \%, 17,4 \%$ and $33,6 \%$ respectively, as showed by the charts bellow.

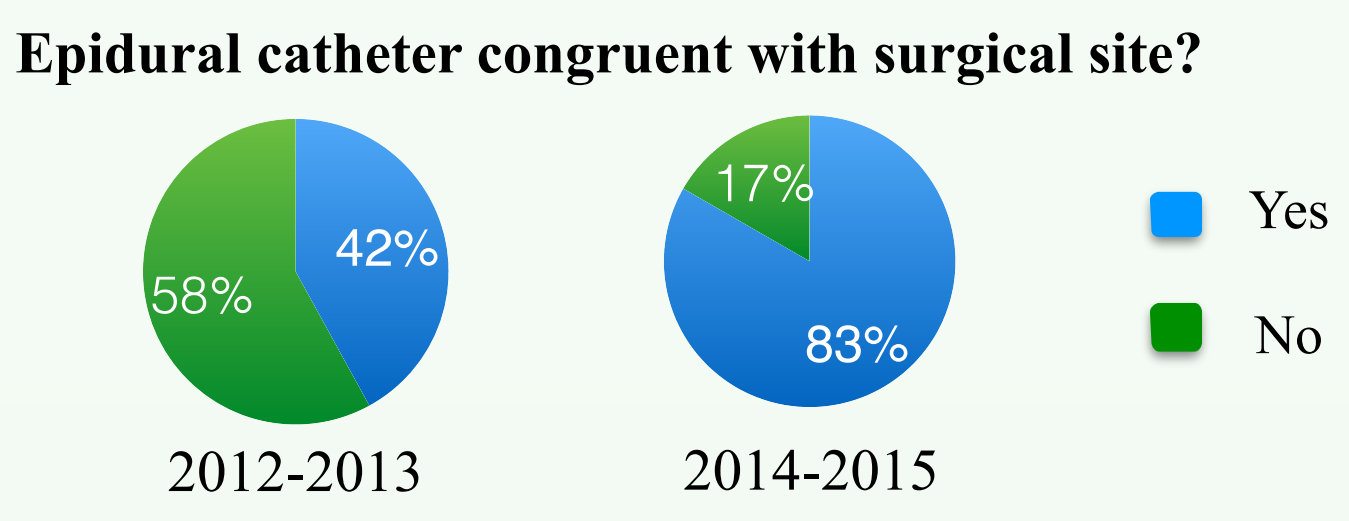

Congruence between catheter incision and surgical site (\%)

Congruent

Incongruent

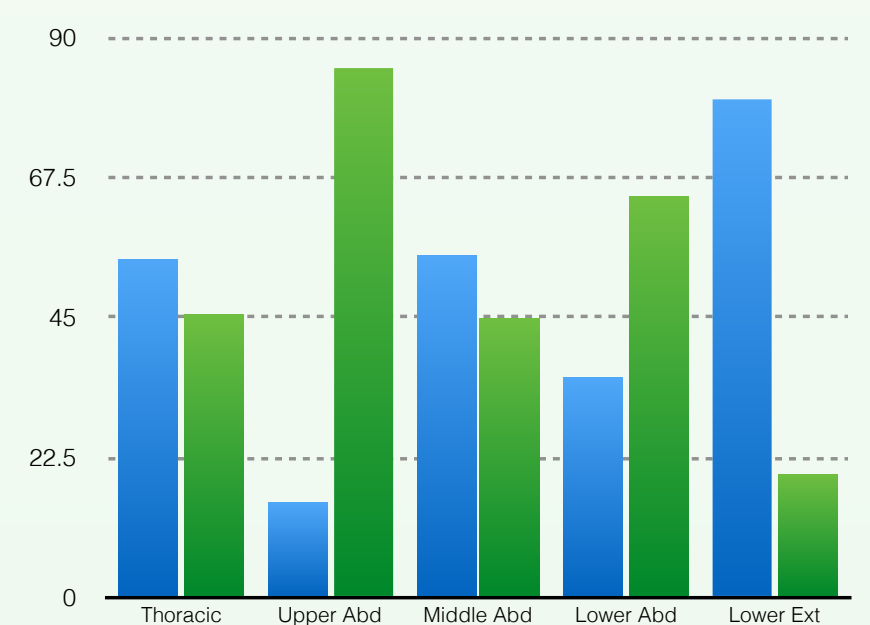

$2012-2013$

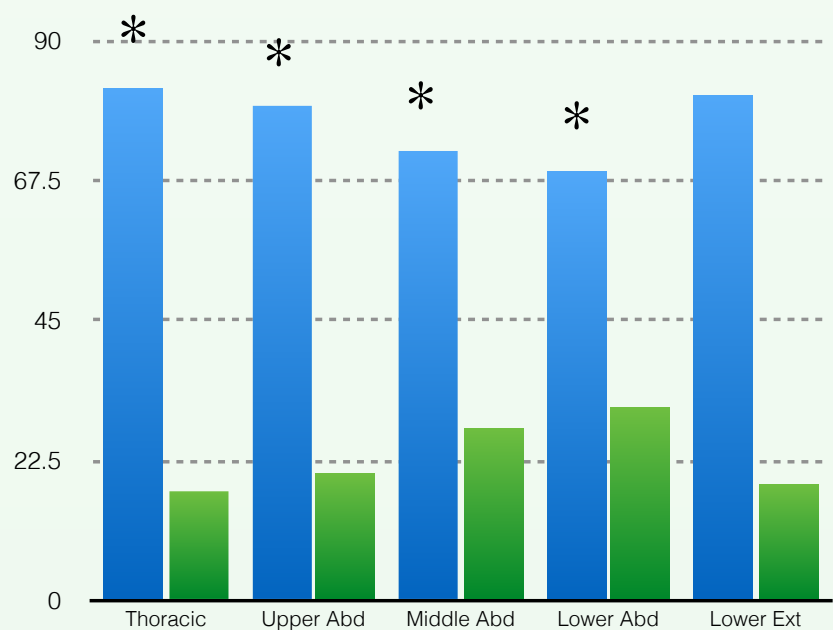

2014-2015
Conclusion

The high incidence of pain in recovery room in 2012 and 2013 may be related to high rates of epidural catheter incongruence. Comparing the analysis of the patients evaluated in 2012-2013 with the ones evaluated in 2015-2016, we found a significant improvement in catheters congruence:

$28 \%$ in thoracic level

$64 \%$ in upper abdominal

$17 \%$ in middle abdominal

$33 \%$ in lower abdominal

Therefore, we confirmed the quality of the initial interventions. We are now motivating the team to maintain these and also implementing new strategies.

References

1) Sommer M, de Rijke JM, van Kleef M et al: The prevalence of postoperative pain in a sample of 1490 surgical inpatients. Eur J Anaesthesiol 25: 267-74, 2008. Anesthesiology, 2013.

2) Christopher Wu, Raja SN: Treatment of acute postoperative pain. Lancet 377: 2215-25, 2011.

3) Ruth M: Enhanced recovery clinical education programme improves quality of post-operative care. BMJ Quality Improvement Reports u208370.w3387 doi: 10.1136/bmjquality.u208370.w3387, 2015. 